AGRICULTURE AND BIOLOGY JOURNAL OF NORTH AMERICA

ISSN Print: 2151-7517, ISSN Online: 2151-7525, doi:10.5251/abjna.2011.2.3.440.447

(C) 2011, ScienceHuß, http://www.scihub.org/ABJNA

\title{
Effect of changing crop rotations on machinery management using
}

\author{
adecision-aid Model
}

\author{
Mysara Ahmed Mohammed ${ }^{1}$, Hassan IbrahimMohammed ${ }^{1}$ Omer El tom Mohamed $^{2}$ and \\ Omran Musa Abbas ${ }^{1}$ \\ ${ }^{1}$ Department of Agricultural Engineering,College of Agricultural Studies, Sudan University of \\ Science and Technology. \\ ${ }^{2}$ Department of Agricultural Engineering Faculty of Agriculture,University of khartoum \\ ABSTRACT
}

\begin{abstract}
To aid decision makers in seasonal planning of machinery in multi-farms a computer model for selecting optimum machinery sizes, machinery scheduling, evaluation of machinery operating plans and estimation of costs of field operations was developed. The developed model employ linear programming and Pert techniques to asses and improve degree of resources utilization . Input data was collected from Rahad irrigation Scheme for the last five years. The model verification was made by comparing actual performance of machinery scheduling program used in Rahad Scheme for two, three and four course rotations in the last five years with outputs generated by the model. Model Application resulted in decreasing demand for tractors and costs of used operations in the Rahad.It resulted in increase in labour demand with increase in cropping intensity and decrease in power usage. Introduction of optimization processes improved power saving and distribution markedly with introduction of summer and winter crops. Sensitivity analysis of the model indicated clear effects of both area cultivated and costs of agricultural operation to changes in input parameters.
\end{abstract}

Keywords: Crop Rotations, Machinery Optimumization,Linear programming , Pert techniques.

\section{INTRODUCTION}

Financing of agricultural machinery to excute mechanized farm cultural operations in optimum time is hindering development of rural areas in most third world countries. Past experience of machinery management and utilization in Sudan showed low level of performance and large heap of written machinery. To solve the problem the government resolved to turn over machinery management to the private sector. To aid in the process of improving performance especially in multi-crop- intra-seasonal rotations (Summer and Winter times) it is urgently needed to develop machinery management and operation model for selecting, planning, scheduling and evaluation of machinery systems. In the literature options used to arrive to this end is to employ operation research techniques namely : Linear programming , Pert and Critical Path analysis ( Botelim , 1990 ,Audsley,1993, Isik and Sabanci ,1993 ).

A crop production machinery system model was developed by Ismail (1994) as a computer interactive model based on the decision - aid concept The results showed that increasing the number of crops in a crop rotation reduces the machinery cost by increasing machinery utilization. Alam and Awal (2001), developed a computer program to select the proper power level based on farm size, and cropping patterns. They concluded that mono - crop system power and power cost requirement are greater than that in multi- crop system. A model for computing farm machinery system (Com Farms) was developed by Lazzari and Mazzetto (1996) to analyze the mechanization problems of Italian arable farms. Once a given crop rotation and a list of operations per crop are entered, the selection offers the user a machinery set (tractors and implements).A mathematical model was developed by Boletim (1990), the computer model quantifies machines and implements and schedules their use to give the minimum cost using linear programming. Hetz (1986) validated a machinery selection model for wheat production in Chile. It was concluded that as the number of crops increased, machinery system and cost per hectare decreased. Ismail (1998) developed Crop Production Machinery System (CPMS) model to predict the machinery requirements and to determine the cost of production. He concluded that multiple crops in a 
rotation will increase machinery and tractor utilization and reduce costs and increase profits.

In Sudan there is no overall interactive and user friendly machinery selection model that deals with all aspects of machinery management and in particular selection, planning, scheduling, implementation , and evaluation in one package. The overall objectives of this study is to develop an analytical, user-friendly computer model for farm machinery management as an aid for farm managers, agricultural engineers and decision-makers. The specific objectives are as follows: to determine optimum machinery sets and their scheduling program to suit various crop rotations, develop a computer cost software, to develop an evaluation program on basis of financial indicators and technical parameters and application of the model for analyzing and improving the performance of farm machinery for the case of Rahad scheme.

\section{MATERIALS AND METHODS}

\section{MOdel DeVELOPMENT:}

Model structure and techniques: The program is menu driven utilizing Visual basic, Excel enviroment and Quantitative Systems for Busines (QSB) software . It is composed of sub- modules. Flow chart of figure (1) shows that input data includes: machinery performance data and economic data. The program process uses transformation functions based on Hunt (1993), theoretical basis , integer linear programming (LP) technique and Pert and Critical Path. The objective function is to minimize overall systems costs. The program matrix consists of 60 decision variables and 14 constraints. Output is displayed in a report showing values of decision variables, costs of field operations, values of addional units of resources (tractors and machinery) and slack or surplus values. The program is made to handle three types of crop rotations and requires instillation of (QSB) working under Windows .

The main features and functions of program modules are as follows:

Module 1: A machinery programming and scheduling module. It computes the required power units and machinery fleet sizes from the user input parameters and the build-in data to complete the field operations during specific period of time. It also generate a monthly scheduling of field operations and machine distribution requirement presented in bar chart form.

Module 2: machinery cost module is used to calculate ownership and operating cost for each field operation.

Module 3: This module is intended to give an intial evaluation of machinery management status. Thus it is directed to generate evaluation outputs in terms of technical (Labor Power- area, Tractor distribution efficiency, Maximum number of tractors tractors) and financial (Internal Rate of Return (IRR), the Net Present Value (NPV), and the Discounted Benefit/Cost Ratio) indicators.

Module 4: Generates the optimum machinery sets to complete field operations at total minimum costs using integer linear programming technique.

Module 5: The final evaluation module. it is equipped with Pert and Critical Path technique to analyze field operations scheduling and calculate time probability(\%) to complete the scheduled operations within the programmed time. 
Agric. Biol. J. N. Am., 2011, 2(3): 440-447

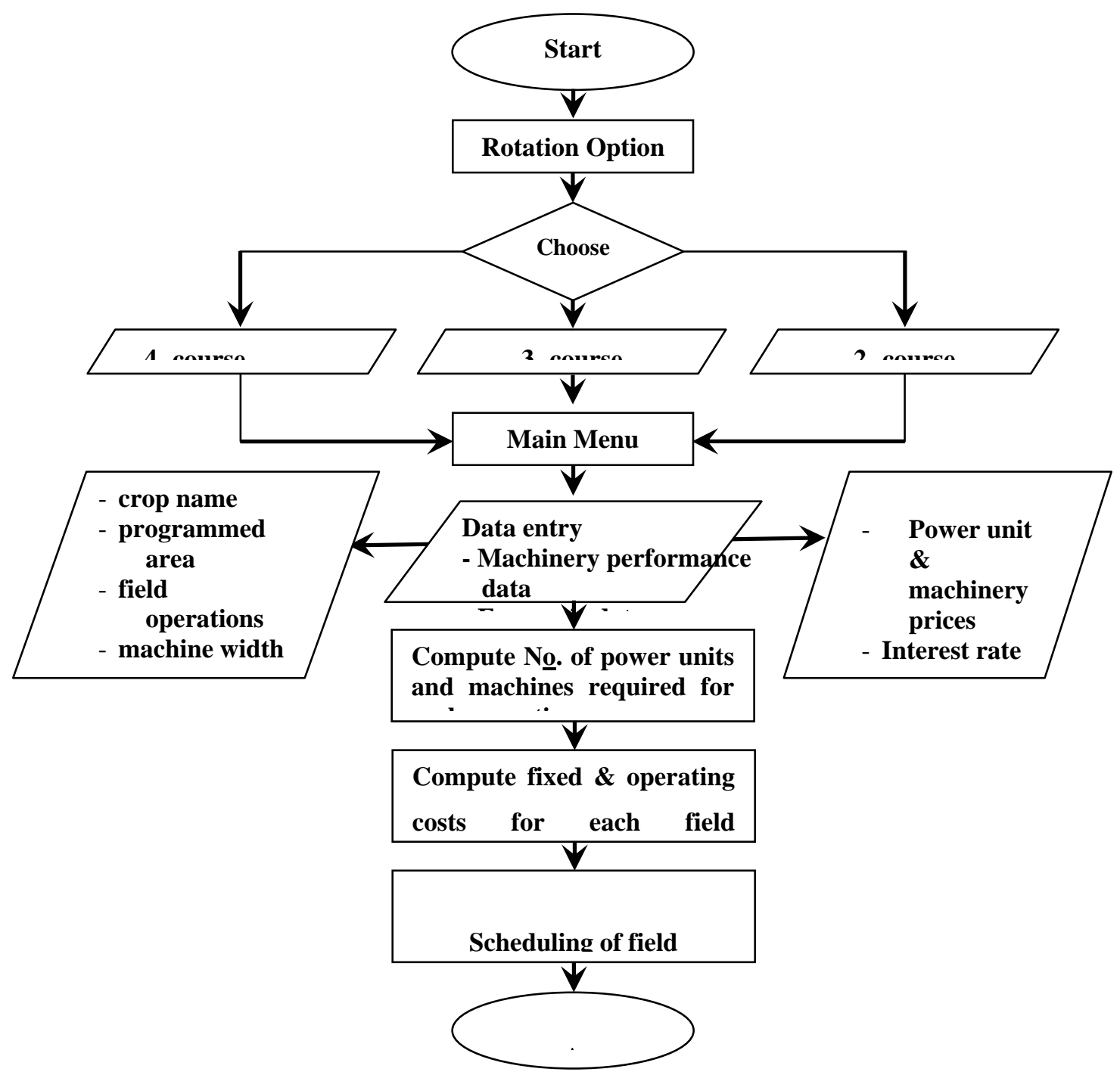

Fig. 1:(a )Program main flowchart 
Agric. Biol. J. N. Am., 2011, 2(3): 440-447

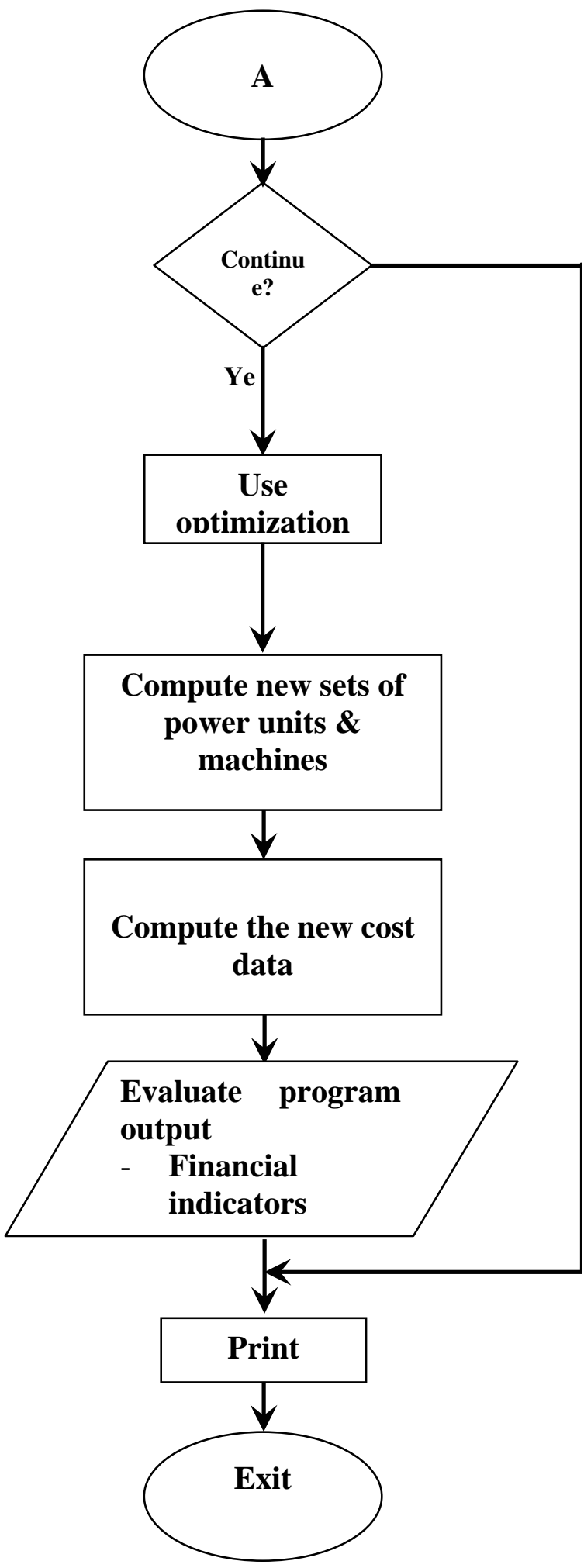

Fig. 1:(b )Program main flowchart(continuation) 


\section{Data Collection AND ANALYSIS:}

The required primary input data for this study was collected using formal and personal contacts with individual agricultural engineers from Rahad scheme (agricultural engineering administration). The Rahad scheme is located on the eastern bank of Rahad River ( 276 km from Khartoum).

The secondary data was collected from bulletins, operation manuals and specifications sheets of machinery and tractors, agricultural operations scheduling program and internal periodical routine reports. The data given was for the season 19992000,2002-2003, 2003-2004 and 2004-2005. Other secondary data was collected from the most relevant published national and international data and periodicals. The main sources of data were the ASAE yearbook (1990),(1993) , Hunt (1993), Agricultural Bank of Sudan Reports and information bulletins from many agricultural machinery dealers in Sudan and world wide. Descriptive statistical techniques were used to analyze the model results using "SPSS" software.These techniques include: t-test, chi-sq. , and analysis of variance. Linear programming and
Pert critical path are utilized to evaluate scheduling data using probability analysis .

\section{RESULTS AND DISCUSSION}

Model Verification: The model output was compared to the system of Rahad mechanization since it's time of initiation in 1977. Figure 1 shows the effect of applying optimization model in reducing number of maximum tractors needed to excute the three types of rotations. As depicted in figure (1), the mathematical model succeeded in reducing the maximum number of required tractors by $30 \%$ for the two course rotation of the Rahad scheme(from 456 to 300 medium tractors of $75 \mathrm{hp}$ ). When the program is applied for three and four course rotations the number of maximum tractors were reduced by $29 \%$. and $16 \%$ for three and four course rotation respectively. It is evident from figure (1) that increasing number of crops in the rotation results in decrease in the number of required tractors. This result is in agreement with Ismail (1998), Hetz (1986)

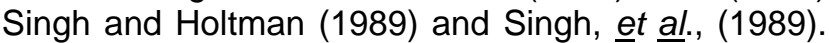
Mas'oud (2005) confirm these results and reported that, increasing the number of crop in a rotation resulted in reducing the number of implements.

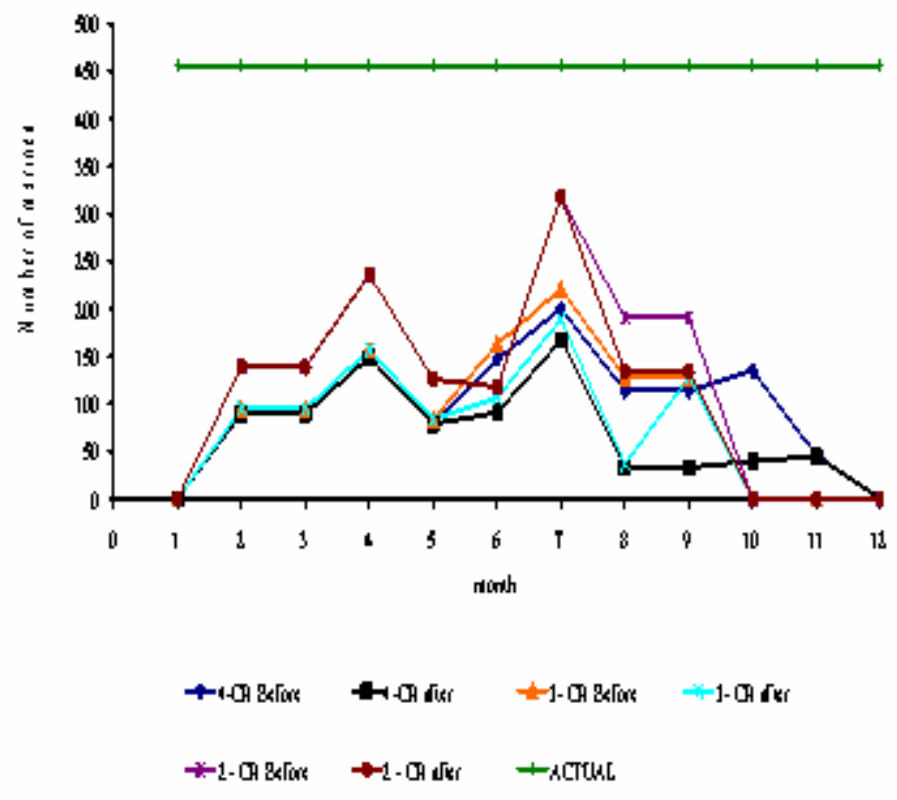

Fig 2.0 Machinery scheduling for three crop rotations. 
Model validation:

This can be achieved by statistically comparing model output with real system of machinery in Rahad scheme. The analysis will take the total cost and direct cost (operating costs) components of (fuel, labor, repair and maintenance costs), number of fleet size, financial indicators and technical parameters. In addition optimization, critical path analysis and Pert theory will be employed as multi-stage approach for validation . It is expected that these techniques can aid decision-maker to take better decision than the actual program and schedules of machinery historically and currently used.

A) Reduction of tractors seasonal peak demand : Table (1) shows the variation of total number of tractors needed by two, three and four crop rotations before and after optimization. The performance measured by improvement percentage may be ranked in decending order as three, four and two course rotation. It is evident from the table that it is difficult to reduce number of tractors for two course rotation because all operations commence in summer period. The improvement in the four course rotation may be attributed to over lap of operations for land preparation for both cotton and ground nut at some time during summer period. Presence of wheat in four course rotation reduce peak demand and overlap by spreading tractor demand over long period . This result is in agreement with Ademosun (1986). The t-test for the nul hypothesis that optimization model reduce the tractors peak demand indicate that this assumption is true for only which differ significantly $(p=0.05)$ from other thee and four course rotations (table 1$)$.
B) Optimization reduction of total cost of operations :

Table (2) shows the total cost of operations for the studied crop rotations before and after optimization . The table indicates that optimization reduced the total cost of operations significently with three and four course rotation as compared to other ones. The least reduction is achieved with two course rotation. This because maximum cost is incured with two course rotation that use maximum number of tractors (865 tractors), while minimum cost is reached with four course rotation (701 tractors).

C) Evaluation of machinery scheduling program: Financial and technical evaluation indicators as shown in table (3) were used to quantify the performance of machinery scheduling programs in Rahad Scheme used for different crop rotations before and after using optimization. This is made to flag out the weak areas by the model to aid to rectify them . Using World Bank (1977) and Gittinger (1986) reference values to evaluate financial indicators , table (3) shows that the results indicate feasible status because NPV and B/C are positive and IRR is more than current finance interest rate $(18 \%)$ for the cases of pre and post optimization . Labour demand parameter increases with increase in cropping intesity (table3) . The bench mark for power - area utilization (interm of tractor power per unit area) is cited by Atia (1986) as $0.04 \mathrm{kw} / \mathrm{ha}$ for Africa and $0.07 \mathrm{kw} / \mathrm{ha}$ for Asia. As given in table (3) power utilization per ha decreased by $50 \%, 25 \%$ and $13 \%$ for two , three and four course rotation respectively. These results are in agreement with the values cited by Atia for Asia and Latin America

Table 1 : Number of tractors before and after optimization

\begin{tabular}{|c||c||c||c|}
\hline \hline Stage & \multirow{2}{*}{$\begin{array}{c}\text { Total No. } \\
\text { Before } \\
\text { Optimization }\end{array}$} & $\begin{array}{c}\text { Total No. After } \\
\text { Optimization }\end{array}$ & Improvement (\%) \\
\hline \hline Rotation & 865 & 808 & 7 * \\
\hline \hline 2 & 737 & 626 & 27 \\
\hline \hline 4 & 701 & 512 & 27 \\
\hline \hline
\end{tabular}

* differ Sig.

Table 2 : Total cost of operations before and after optimization

\begin{tabular}{|c||c||c||c||}
\hline \multicolumn{1}{|c|}{ Stage } & \multirow{2}{*}{$\begin{array}{c}\text { Before } \\
\text { Optimization }\end{array}$} & After Optimization & Improvement (\%) \\
\hline \hline Rotation & 8645 & 7898 & 9 \\
\hline \hline 2 & 8227 & 6088 & 26 \\
\hline \hline 4 & 7460 & 4998 & 33 \\
\hline
\end{tabular}


Agric. Biol. J. N. Am., 2011, 2(3): 440-447

Table 3 : Financial and technical indicators for the three different rotations

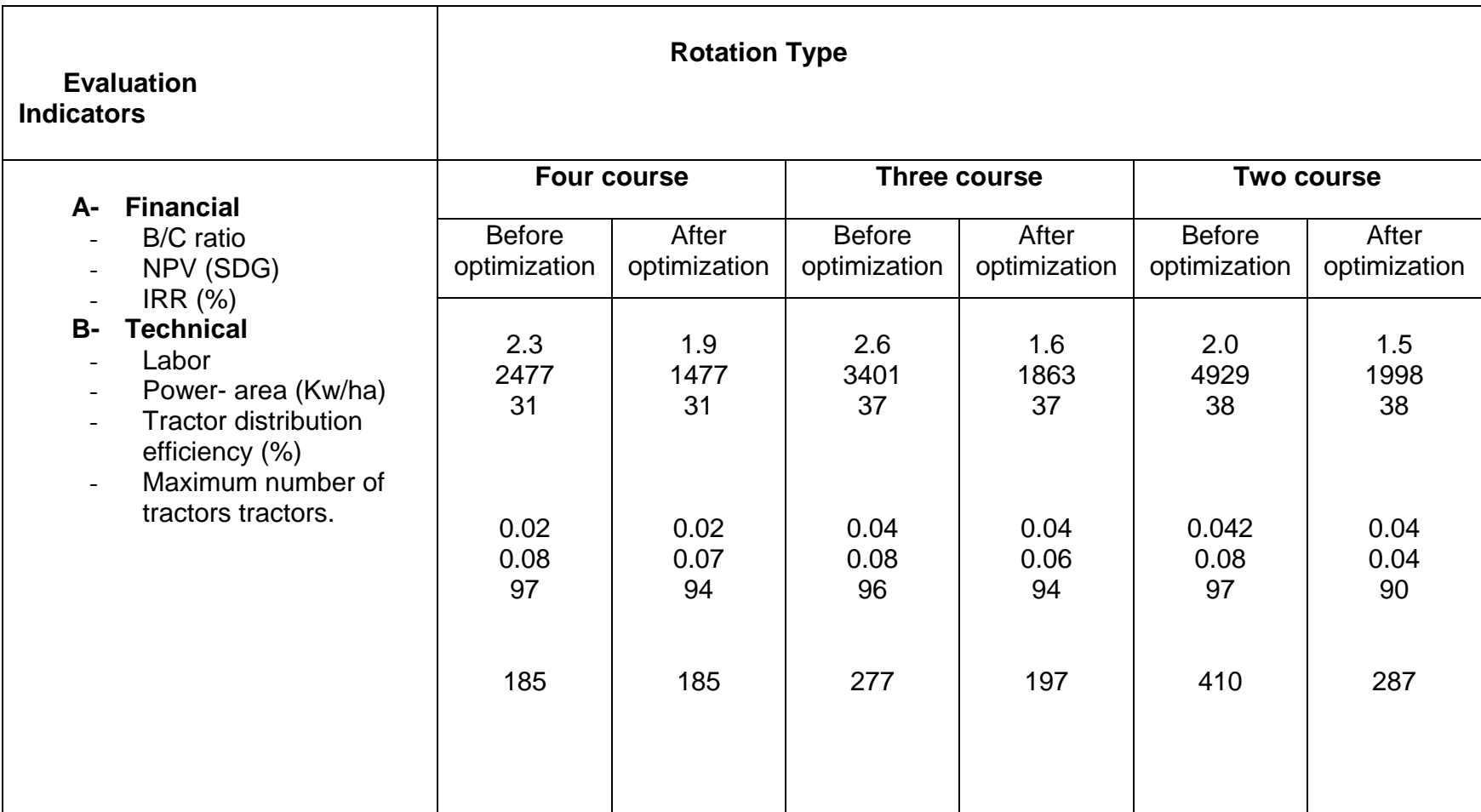

As given in table (3) tractor distribution efficiency (TE) has been slightly improved by optimization by $3-7 \%$ for the various crop rotations. This may be due to the seasonality of cultural practices and use of supplementary irrigation where peak demand for machine utilization concentrate at specific time of the year (Fig.1). The maximum number of tractors decrease with increase of a number of crops in the rotation (table3). This is due to decrease of area programmed for each crop when number of crops is increased. Optimization resulted in decreasing the peak demand for tractors in the two and three course rotations by $30 \%$. In contrast the optimization did not reduce the peak demand of the four course rotation . This is in line with Ismail,(1994) .

Machinery evaluation by Pert and Critical Path techniques:: Table (4) shows the project total completion time (days) for the different crop rotations at $100 \%$ probability . The table indicates that: heavy discing is the most critical operation irrespect of type of rotation. Time for completion of all operations is positively related to increase in number of crops in the rotation .

Table (5) indicates that to achieve $100 \%$ probability level of implementation 99.5, 94, and 87.7 days are needed for four, three and two course rotation. The table shows the time needed to complete the project at 80 and 60 level of probability. This is given to help decision maker to adjust his implementation plan in case of shortage of resources (finance, material or human resources). Utilization of the optimization model results in time saving of 9,11 and $13 \%$ at $100 \%$ probability level for two, three and four course rotations.

Table 4 Number of critical paths for three crop rotations

\begin{tabular}{|c|l|cc|}
\hline Rotation & Name of Critical Paths & \multicolumn{2}{|c|}{$\begin{array}{c}\text { Time to finish at 100\% } \\
\text { probability (days) }\end{array}$} \\
\hline 4 & H.Discing & 100 & $(2.33)^{\star}$ \\
\hline 3 & H.Discing & 94 & $(1.17)$ \\
\hline 2 & H.Discing & 88 & $(1.16)$ \\
\hline
\end{tabular}

* Standard Deviation 
Table 5 Probability analysis for four, three and two course rotation

\begin{tabular}{|c|c|c|c|}
\hline \multirow{2}{*}{ Probability level } & \multicolumn{3}{|c|}{ Completion time required (in days) } \\
\cline { 2 - 4 } & 4 course rotation & 3 course rotation & 2 course rotation \\
\hline 50 & 88.53 & 87.7 & 81.9 \\
\hline 60 & 88.65 & 88 & 82.2 \\
\hline 80 & 90 & 88.7 & 82.9 \\
\hline 100 & 99.5 & 94 & 87.7 \\
\hline $\begin{array}{c}\text { Tima saving \% (100\% prob. to } \\
\text { actual Rahad time) }\end{array}$ & 114 & 105 & 96 \\
\hline
\end{tabular}

\section{CONCLUSION AND RECOMMENDATIONS}

Use of optimization model ,based on linear programming and Pert technique, to assess impacts of different types of crop ratations in Rahad Scheme was found to reduce peak demand for tractors and reduce over all machinery costs.

Tests of the model verification and analysis on statistical basis for the case of Rahad scheme reveals the opportunity to improve machinery management (power utilization time and tractor distribution) in Rahad scheme. Validity and sensitivity tests of the model in comparison with the original design program of machinery in the Rahad scheme gave a confidance, robustness and reliability to use the program for any multi - crop farm. Results of model application indicates that rotations with multicrop using summer and winter cropping reduced and spread the peak machinery demand as compared to the tied two course crop rotation.

\section{REFERENCES}

Ademosun , O.C. 1986. Determination of the optimum capacities of farm machines to adapt for a medium scale multicrop production. Agricultural system ( 21 ) 33-57 . Elsevier Applied Science Publishers Ltd. England.

Alam ,M. and Awal, M.A., 2001. Selection of Farm Power by using a Computer Program .Agricultural Mechanization in Asia, Africa and Latin America (AMA) 32(1).

ASAE , 1990, 1993. Agricultural Machinery Management Data, American Society of Agricultural Engineers (ASAE ) standards. St. Joseph. MI_49085, USA.

Atia , I. M. ,1986. Economic of Agricultural Mechanization. Egyptian printing House. Egypt.

Audsley , E; E. 1993 . Labor , Machinery and cropping planning . Proceeding Xxvc 10 STA- Congress . 83-88
Boletim , T. C .,1990. Optimized planning of the use of agricultural machinery

Gittinger , J.P., 1986 , Economic Analysis of Agricultural projects. Second edition - John Shopkins .uni. press London.

Hetz , H.E. 1986 . Farm machinery needs according to cultivated area. Tillage Intensity and crop rotation . Agro. Sur. 14 (2) : 67-77.

Hunt, D. 1993. Farm Power and Machinery Management $.8^{\text {th }}$ edition . lowa State University Press, Ames, lowa, U.S.A.

ISik, A., and Sabanei , A.A., 1993. Computer Model to select Optimum Size of Farm Machinery and Power for Mechanization Planning . Agricultural Mechanization in Asia, Africa and Latin America , 24 (3) : 68-72.

Ismail , W., I. , 1994. Expert System for Crop Production Machinery Systems. Agricultural Mechanization in Asia , Africa and Latin America , 25 (30) : 55-62.

Ismail , W. I., 1998. Cost Analysis Model for Crop production Machinery System . Agricultural Mechanization in Asia, Africa and Latin America (AMA) vol.(29) NO. 4 : 56-60.

Lazzian , M. and F. Mazzetto.(1996). APC model for selecting multicropping farm machinery systems. Computers and Electronics in Agric. 1996, 14:1 (43 59).

Masoud , F. H. , 2005. A Computer Model for Farm Machinery Selection .ph.D. Thesis,$U$.of K.

Singh , D., and Holtman , J.B. 1989 . A Heuristic Agricultural Field Machinery selection Algorithm for Multi -crop Farms . Trans. Of ASAE, 1979: 763-770.

Singh, D. , T.H. Burkhard , J.B. Holtman , L.J. connor , and L.S. Robertson . 1989 . Field Machinery Requirements as influnced by Crop Rotations and Tillage practices . Trans. of ASAE vol. $22,702-708$.

World Bank . 1977. World Bank Supplemental procurement guide for Bank staff. World Bank, New York. 